\title{
INVESTIGAÇÃO DA HFC NO ENSINO DE CIÊNCIAS DO IFRN - CAMPUS CAICÓ
}

\author{
Paulo Ricardo Amorim da Silva ${ }^{1}$ \\ ORCID: 0000-0002-4316-2101 \\ ÍtAlo BATISTA DA Silva ${ }^{2}$ \\ ORCID: 0000-0001-5135-9943 \\ Joseri PEDRO DE LIMA ${ }^{3}$ \\ ORCID: 0000-0002-5432-9253 \\ Eliete da Silva Ramalho ${ }^{4}$ \\ ORCID: 0000-0002-2695-2080
ERIQUes WANDERLEy da Silva ${ }^{5}$
ORCID: 0000-0003-1522-1650

\begin{abstract}
Resumo: A História e Filosofia da Ciência (HFC) exercem papel fundamental na aprendizagem das teorias científicas e nos debates de cunho científico no ambiente escolar, no que diz respeito às raízes do conhecimento. Nesse sentido, o Grupo de Estudo e Pesquisa em Ensino de Física (GEPEF) do IFRN Campus Caicó, por meio de pesquisa aplicada por alguns de seus membros, realizou o presente estudo com o objetivo de investigar a inserção de tópicos de HFC nas aulas dos docentes de Ciências (Física, Química e Biologia) do Ensino Médio e Integrado ao Técnico do IFRN - Campus Caicó. A pesquisa propõe fazer um estudo por meio da aplicação de um questionário adaptado de Martins (2006) pelo GEPEF do IFRN - Campus Caicó, procura
\end{abstract}

\footnotetext{
Professor Doutor do IFRN Campus Caicó e-mail: paulomdr_@hotmail.com

Graduando de Licenciatura em Física (IFRN - Campus Caicó) e-mail: italo.batista@ifrn.edu.br

3 Graduando de Licenciatura em Física (IFRN - Campus Caicó)e-mail: joseri1o.jp@gmail.com

4 Graduando de Licenciatura em Física (IFRN - Campus Caicó) e-mail: elietelinda@gmail.com

5 Graduando de Licenciatura em Física (IFRN - Campus Caicó) e-mail: eriques.sil@outlook.com
} 
destacar e diagnosticar se estes professores fazem a utilização da HFC em suas aulas e priorizam proporcionar aos alunos o conhecimento de como se chegou e de onde partiram tais conteúdos ensinados em sala de aula, além do papel do docente e suas perspectivas diante desse processo de ensino-aprendizagem. A maioria dos docentes relata que já utilizou em suas aulas a inserção de tópicos de HFC, mesmo que em muitos casos de maneira introdutória aos conteúdos expostos, demonstrando um significativo interesse em estudar e trabalhar HFC com o alunado. Por fim, observa-se que as escolas hoje no Brasil preocupam-se mais com exames de seleção para o ingresso ao Ensino Superior, como por exemplo, o Enem, tornando a carga horária dessas disciplinas pequena, dificultando de forma geral a introdução da HFC nas aulas de Ciências.

Palavras-chave: História. Filosofia. Ciência. Formação. Docente.

\title{
HFC RESEARCH IN SCIENCE EDUCATION AT IFRN - CAMPUS CAICÓ
}

\begin{abstract}
The History and Philosophy of Science (HFC) plays a fundamental role in the learning of scientific theories and scientific debates in the school environment, with regard to the roots of knowledge. In this sense, the Group of Study and Research in Physics Teaching (GEPEF) of the IFRN - Campus Caicó, through applied research by some of its members, carried out the present study with the objective of investigating the insertion of HFC topics in the classes of science teachers Physics, Chemistry and Biology) of high school and integrated with IFRN technician - Campus Caicó. The research proposed to do a study through the application of a questionnaire adapted from Martins (2006) by the GEPEF of IFRN - Campus Caicó, seeking to highlight and diagnose if these teachers make use of HFC in their classes, prioritizing to provide students with knowledge how and where they came from, the role of the teacher and their perspectives in the teaching-learning process. Most teachers reported that they have already used HFC topics in their classrooms, even though in most cases they have introduced introductory content, demonstrating a significant interest in studying and working with HFC students. Finally, it was observed that schools in Brazil today are more concerned with selection exams at the entrance to higher education, such as Enem, making the hours of these subjects small, making it difficult in general to introduce HFC in science classes.
\end{abstract}

Keywords: History. Philosophy. Science. Teacher. Training.

\section{INVESTIGACIÓN DE LA HFC EN LA ENSEÑANZA DE LAS CIENCIAS DEL IFRN - CAMPUS CAICÓ}

Resumen: La Historia y Filosofía de la Ciencia (HFC) desempeñan un papel fundamental en el aprendizaje de las teorías científicas y en los debates de carácter científico en el ambiente escolar, en lo que se refiere a las raíces del conocimiento. En este sentido, el Grupo de Estudio e Investigación en Enseñanza de Física (GEPEF) del IFRN Campus Caicó, a través de investigación aplicada por algunos de sus miembros, realizó el presente estudio, con el objetivo de 
investigar la inserción de tópicos de HFC en las clases de los docentes de ciencias (Física, Química y Biología) de la Enseñanza Media e Integrado al Técnico del IFRN - Campus Caicó. La investigación propuso hacer un estudio a través de la aplicación de un cuestionario adaptado de Martins (2006) por el GEPEF del IFRN - Campus Caicó, busca destacar y diagnosticar si estos profesores hacen la utilización de la HFC en sus clases y a la vez priorizan proporcionar a los alumnos el conocimiento de cómo se llegó y de dónde partieron tales contenidos enseñados en el aula, además del papel del docente y sus perspectivas ante este proceso de enseñanza-aprendizaje. La mayoría de los docentes relata que ya se las utilizó en sus clases la inserción de tópicos de HFC, aunque en muchos de los casos de manera introductoria a los contenidos expuestos, demostrando un significativo interés en estudiar y trabajar HFC con el alumnado. Por último, se observó que las escuelas hoy en Brasil se preocupan más con exámenes de selección para el ingreso a la Enseñanza Superior, como por ejemplo, el Enem, haciendo la carga horaria de esas disciplinas pequeña, dificultandolo de forma general la introducción de la introducción HFC en las clases de Ciencias.

Palabras clave: Historia. Filosofía. Ciencia. Formación. Docente.

Submetido em: 07/01/2019.

Aceito em: 14/05/2019.

\section{INTRODUÇÃO}

A difícil absorção e entendimento dos conteúdos das áreas de Ciências nas disciplinas de Física, Química e Biologia servem como ponto de vista para encontrar caminhos didáticos, teóricos ou práticos para facilitar e motivar o processo de ensino-aprendizagem dessas disciplinas.

A Física, por exemplo, de acordo com os escritos de Máximo e Alvarenga (2003) é a ciência que estuda os fenômenos que ocorrem na natureza, com a preocupação de direcionar ao conhecimento dos fenômenos naturais, conhecimentos referentes a um novo mundo criado pelo homem e ampliam cada vez mais esse campo de estudo para tornar nossas vidas profundamente envolvidas por ela. Para Feltre (2005), a Química é a Ciência das Substâncias - das suas propriedades e do que acontece quando se misturam umas com as outras. Já a Biologia, dentre as Ciências naturais, de acordo com Lopes e Rosso (2010), estuda a vida e os organismos vivos. É importante enfatizar que cada uma destas ciências divide-se em campos especializados ou ramos para uma melhor compreensão dos conteúdos.

Para Silva e Tavares (2005), a Ciência procura discutir os princípios básicos dos fenômenos que ocorrem na natureza, procura descobrir as causas desses 
fenômenos e como eles influenciam na nossa vida, tendo como objetivo único a melhoria das condições de vida da humanidade. As Ciências -Física, Química e Biologia- também se direcionam neste caminho.

Partindo da problemática do processo de ensino-aprendizagem das ciências, mais precisamente da dificuldade apresentada por discentes nas disciplinas de Física, Química e Biologia no entendimento/compreensão dos conteúdos de forma clara devido a metodologias tradicionalistas na Educação, acredita-se que por meio do ensino das raízes do conhecimento, pode-se encontrar uma solução. O professor no processo de ensino-aprendizagem tradicional acaba sendo um mero expositor de conteúdos por meio de fórmulas, cálculos matemáticos, teorias, conceitos, leis e definições específicas de cada área do conhecimento, sem dar significado a sua importância para a vida do discente, podendo gerar no aluno concepções errôneas quanto ao fazer científico.

Com o intuito de solucionar essa problemática, foi feito um estudo bibliográfico sobre História e Filosofia da Ciência (HFC) na formação docente e investigação da sua inserção na sala de aula nos professores das Ciências naturais básicas do integrado no IFRN - Campus Caicó.

O trabalho trata-se de uma pesquisa investigativo-qualitativa, tendo como objetivo principal investigar, por meio de um questionário adaptado de Martins (2006), a utilização da História e Filosofia da Ciência na formação de professores de ciências e o uso desta nas aulas de Física, Química e Biologia no Ensino Médio integrado ao técnico do IFRN - Campus Caicó, ressaltando que a adaptação das questões foi feita pelo Grupo de Estudo e Pesquisa em Ensino de Física (GEPEF) do IFRN - Campus Caicó.

\section{REFERENCIAL TEÓRICO}

A História e Filosofia da Ciência (HFC) se faz presente em todas as descobertas, desde a Antiguidade até os dias atuais. Nesse sentido, Rosa (2012) afirma que na Pré-História, com o aparecimento da escrita, ainda predominava a explicação teológica das coisas, na qual as Escrituras a respeito da Criação do Universo, da Terra e do Homem eram consideradas as mais corretas. No Renascimento, por exemplo, com as grandes transformações sociais, econômicas, filosóficas, políticas, religiosas, culturais e técnicas na Europa ocidental no início do século XIII iniciaram discussão sobre a curiosidade e a necessidade 
de compreensão do Mundo natural por meio de temas, conceitos e tabus para tentar unir a razão e a revelação.

Segundo Peduzzi et. al. (2012), a HFC investiga os fatos históricos da Ciência, cuja origem dá-se a partir de documentos e acontecimento e podem conter crenças e filosofias do historiador, já que a análise dos registros pode ser compreendida pela própria construção. De acordo com Martins (2006), a HFC caracteriza-se como campo de estudo que sofre influências de duas abordagens: internalista, quando compreendem os acontecimentos; teorias e conceitos que se confrontam e se comprovam; e externalista, quando relaciona perspectivas sociais, políticas e econômicas do espaço-tempo em que a Ciência se encontra. Partindo desta perspectiva, entende-se que a História da Ciência procura um saber composto e pensativo que seja apropriado a englobar essas duas abordagens, já que existem materiais que tratam a HFC apenas como internalista.

De um modo geral, as razões para a introdução da HFC na sala de aula são: a humanização do conteúdo a ser lecionado; o enriquecimento no saber científico, já que socializa e debate seus tópicos de difícil compreensão; o realce da importância da Ciência como Cultura; o destaque da variável do saber científico; e possibilidade de um melhor entendimento sobre Ciência (MATTHEWS, 1995; HÖTTECKE, SILVA, 2011).

Segundo Martins (2006), a História das Ciências não pode substituir o ensino comum das Ciências, mas deve ser complementada de várias maneiras. Para as inter-relações entre ciência, tecnologia e sociedade, é necessário o estudo adequado de alguns episódios históricos, ressaltando que a Ciência não está isolada das outras, mas faz parte do desenvolvimento histórico, de uma Cultura, de um mundo humano, sofrendo influências e persuadindo muitos aspectos da sociedade. Então, o estudo correto de alguns contextos, permite ao aluno perceber o processo social e, gradualmente, vai construindo seus conhecimentos, tendo uma percepção mais concreta e correta da realidade da natureza da Ciência.

A representação dos movimentos de CTS, segundo Santos (2001), coloca em evidência a necessidade de uma abordagem histórico-filosófica dos conteúdos das disciplinas científicas, bem como as reformas educacionais que apontam para a necessidade da contextualização histórico-social do conhecimento científico em nosso país, considerando, dessa forma, a contribuição da HFC (os Parâmetros Curriculares Nacionais e os PCN+). Alguns autores, como GIL PÉREZ (1993), MATTHEWS (1994), VANNUCCHI (1996), 
PEDUZZI (2001), entre outros, defendem que a HFC nas salas de aula deve ser inserida nos diversos níveis de ensino (Fundamental, Médio e Superior).

\section{METODOLOGIA}

O Grupo de Estudo e Pesquisa em Ensino de Física (GEPEF) do IFRN -Campus Caicó, nas reuniões realizadas semanalmente, constatou a necessidade de pesquisar e investigar temas voltados para motivar/facilitar o ensino-aprendizagem da Física. Um dos temas discutidos em alguns dos encontros direcionou-se à História e Filosofia da Ciência (HFC) no ensino de ciências no âmbito escolar.

A partir disso, construiu-se a presente pesquisa que se propõe a fazer uma investigação sobre a utilização da História e Filosofia da Ciência na formação de professores de Ciências e sua inserção nas aulas de Física, Química e Biologia, por meio da aplicação de um questionário adaptado (ANEXOS) de Martins (2006) pelo Grupo de Estudo e Pesquisa em Ensino de Física (GEPEF) do IFRN - Campus Caicó. Procura-se destacar e diagnosticar se estes professores fazem a utilização da HFC em suas aulas com o objetivo de proporcionar aos alunos o conhecimento de como se chegou e de onde partiram tais conteúdos a serem tratados, o papel do docente e suas perspectivas diante desse processo e responder a seguinte pergunta: quais contribuições na inserção da História e Filosofia da Ciência na sala de aula podem levar ao processo de ensino aprendizagem das Ciências Naturais?

O método utilizado para a coletânea dos dados foi um questionário adaptado em uma sequência de perguntas discursivas e objetivas entregue aos professores, com o intuito de descobrir qual contato possuíram ou possuem com HFC durante e depois da graduação e se a utilizam em suas aulas, explicando como ocorre este processo. Também, investigaram-se quais as principais dificuldades em inserir a HFC na sala de aula. Com a intenção de conceder aos docentes uma posição mais confortável para expor suas ideias, a identificação não foi obrigatória. De acordo com o modelo de pesquisa investigativo-qualitativa, tendo em vista a análise por números, das diversas posições tomadas por docente. A utilização da forma quantitativa tem-se mostrado de maior relevância, o que acaba nos proporcionando um complemento entre essas duas formas de análise. Por fim, após a coletânea dos dados por meio da aplicação dos questionários, segue-se para o processamento e análise dos resultados fundamentados por discussão do objeto de pesquisa em questão. 


\section{RESULTADOS E DISCUSSÕES}

De acordo com a análise dos dados apresentados nos questionários respondidos pelos professores de Ciências (Física, Química e Biologia) do IFRN - Campus Caicó, formulou-se a seguinte Tabela 1 do público objeto de investigação dessa pesquisa.

Os dados analisados, conforme cada área das Ciências, segundo o questionário adaptado de Martins (2006), em Anexo, foi do quadro de docentes do IFRN - Campus Caicó. A maioria dos profissionais de educação dessa instituição das áreas de Física, Química e Biologia responderam ao item "Formação" do presente questionário apenas com o nome do curso e só 02 (dois) professores preencheram com título de Doutorado em suas áreas de formação acadêmica. Todos os docentes envolvidos na pesquisa são do gênero masculino e apresentaram uma média de idades entre 33 e 38 anos. Observa-se na Tabela 1 também um número superior de professores de Física que os de Química e de Biologia existentes no Campus, isto devido à instituição ofertar Curso Superior de Licenciatura em Física.

Tabela 1: Público da pesquisa.

\begin{tabular}{|c|c|c|c|c|c|c|c|c|}
\hline \multirow{2}{*}{$\begin{array}{l}\text { ÁREAS DAS } \\
\text { CIÊNCIAS }\end{array}$} & \multirow{2}{*}{$\begin{array}{l}\text { IDADE } \\
\text { MÉDIA }\end{array}$} & \multicolumn{2}{|c|}{ Sexo } & \multirow{2}{*}{ DOCENTES } & \multicolumn{4}{|c|}{ FoRMAÇÃo } \\
\hline & & MASC. & FEM.. & & Grad & MEST & Dout & PHD \\
\hline $\begin{array}{c}\text { Física } \\
\text { (6 docentes) }\end{array}$ & 33,8 & $\begin{array}{c}6 \\
100 \%\end{array}$ & - & $\begin{array}{c}6 \\
(100 \%)\end{array}$ & $\begin{array}{c}1 \\
(16,66 \%)\end{array}$ & $\begin{array}{c}3 \\
(50 \%)\end{array}$ & $\begin{array}{c}1 \\
(16,66 \%)\end{array}$ & $\begin{array}{c}1 \\
(16,66 \%)\end{array}$ \\
\hline $\begin{array}{l}\text { Química } \\
\text { (1 docente) }\end{array}$ & 35 & $\begin{array}{c}1 \\
50 \%\end{array}$ & - & $\begin{array}{c}1 \\
(50 \%)\end{array}$ & - & $\begin{array}{c}1 \\
(100 \%)\end{array}$ & - & - \\
\hline $\begin{array}{c}\text { Biologia } \\
\text { (1 docente) }\end{array}$ & 38 & $\begin{array}{c}1 \\
50 \%\end{array}$ & - & $\begin{array}{c}1 \\
(50 \%)\end{array}$ & - & $\begin{array}{c}1 \\
(100 \%)\end{array}$ & - & - \\
\hline
\end{tabular}

\section{FONTE: OS AUTORES}

Dentre os professores que participaram da pesquisa, sete (Física e Biologia) responderam que têm o interesse em estudar o tema História e Filosofia da Ciência, porém um docente da Física respondeu que seu interesse é parcial, mencionando a sua discordância, quanto aos tópicos isolados e sua concordância em relação a uma proposta que todo livro ou aula se referencie pela 
temática da HFC. Também, o professor de Química explicou o seu interesse em parte, destacando um ponto de vista que é necessário ter o conhecimento do contexto histórico onde são produzidos os conhecimentos científicos.

Em relação ao fato de os docentes terem cursado alguma disciplina que abordasse a HFC em sua graduação, $6(66,6 \%)$ professores responderam que sim, sendo esses da área de Física, na qual um desses profissionais mencionou que participou de um grupo de pesquisa sobre História e Filosofia da Ciência e que também trabalhou o tema em questão no Ensino de Física em seu Trabalho de Conclusão de Curso - TCC. Já os demais da área de Química e Biologia $(33,4 \%)$ responderam que não tiveram nenhuma disciplina relacionada ao tema.

Com base na Tabela 2 que faz referência às respostas da quarta pergunta do questionário, percebe-se que a falta de material didático adequado para a introdução da História e Filosofia da Ciência nas aulas de Ciência torna-se a principal dificuldade da inserção deste conteúdo na sala, seguida pela formação docente e pelo encurtamento da carga horária das disciplinas de Ciências, em especial docentes de Física, grupo que concentrou o maior número de professores participativos da pesquisa.

TABela 2:PRESPOSTASA QUESTÃO4DOQUESTIONÁRIO:NASUAOPINIÃO, QUAISAS DIFICULDADES PARA SE TRABALHAR COM A HISTÓRIA E FILOSOFIA DA CIÊNCIA NO ENSINO MÉDIO?

\begin{tabular}{|c|c|}
\hline $\begin{array}{c}\text { DIFICULDADES QUANTO À UTILIZAÇÃo } \\
\text { DA HFC NO ENSINO MÉDıo }\end{array}$ & TOTAL \\
\hline Carga horária curricular pequena & 5 \\
\hline Falta de material didático adequado e atualizado & 3 \\
\hline Formação de professores e adequação dos currículos & 1 \\
\hline Tarefa do professor de História & 1 \\
\hline $\begin{array}{c}\text { A não disposição dos docentes e discentes à } \\
\text { realização de leituras. }\end{array}$ & 1 \\
\hline $\begin{array}{c}\text { A quantidade de conteúdos que diminuem o tempo } \\
\text { da abordagem dos contextos históricos. }\end{array}$ & \\
\hline
\end{tabular}

FONTE: OS AUTORES.

No que diz respeito à questão 5 , os professores responderam de acordo com Tabelas 3 e 4 a seguir. 
Ta bela 3: Prespostas da questão 5: Dos CONTeÚdos CURRICULARES da Física noEnsino MÉDIO, QUAL (OU QUAIS) VOCÊ CONSIDERA MAIS DIFÍCIL DE SER TRABALHADO ATRAVÉS DA INCORPORAÇÃODETÓPICOSDAHISTÓRIAEFILOSOFIADACIÊNCIA?EQUAL(OUQUAIS)OMAISFÁCIL?

\begin{tabular}{|c|c|c|}
\hline \multicolumn{2}{|c|}{ Conteúdos da Física PARA SE TRABALHAR COM A HFC } \\
\hline FÁcEIS & Difíceis & Total DE DOCENTES \\
\hline $\begin{array}{c}\text { Mecânica, eletromagnetismo } \\
\text { e Física moderna }\end{array}$ & Óptica e ondas & 3 \\
\hline
\end{tabular}

FONTE: OS AUTORES.

Os demais docentes da Física responderam à pergunta da seguinte maneira:

"Não há algum tópico mais fácil ou mais difícil, mas a dificuldade em encontrar materiais para subsidiar alguns tópicos."

"Os conteúdos mais difíceis eram aqueles conteúdos que envolvem um tratamento mais matemático."

"Eu teria que ver todo o conteúdo para responder."

Tabela 4: Respostas da questão 5: Dos conteúdos curriculares da Química no Ensino MÉdIO, QUAL (OU QUAIS) VOCÊ CONSIDERA MAIS DIFÍCIL DE SER TRABALHADO ATRAVÉS DA INCORporação de tópicos da História e Filosofia da CiênCIA? E qual (OU QUaIS) O Mais fácil?

\begin{tabular}{|c|c|c|}
\hline \multicolumn{2}{|c|}{ Conteúdos da Química PARA SE TRABalHar COM A HFC } \\
\hline FÁcEıs & Difíceis & Total DE DOCENTES \\
\hline $\begin{array}{c}\text { "O mais fácil com certeza é } \\
\text { o equilíbrio químico devido } \\
\text { às conexões da indústria e o } \\
\text { conhecimento científico." }\end{array}$ & $\begin{array}{c}\text { "O mais difícil com certeza é o } \\
\text { de funções inorgânicas, pois } \\
\text { só temos acesso às aplicações." }\end{array}$ & 1 \\
\hline
\end{tabular}

FONTE: OS AUTORES.

Não houve resposta do professor de Biologia à referida pergunta. Por meio das respostas dos professores de Física, em maior número, observa-se que ocorreu um consenso em 50\% (3 docentes), destacando os mesmos conteúdos entre os mais fáceis e os mais difíceis; enquanto os outros 3 divergiram nas respostas. Isso denota o caráter subjetivo da dificuldade de abordar tópicos de HFC em sala de aula.

Nesse sentido, a maioria dos professores relata que já usou tópicos da HFC em sua prática docente, como seguem respostas dos professores a respeito desta 
questão 6 (Você, como professor, já tentou trabalhar tópicos de História e Filosofia da Ciência na sua prática docente? Poderia relatar o que você fez de maneira mais específica (que tipo de atividade realizou))?:

"Sim. De maneira geral (genérica) e expositiva. Aulas de sistemas métricos e gravitação são clássicas neste contexto." (Professor de Física).

"Sim. Sempre no início de qualquer assunto. Tento mostrar como o conteúdo foi construído, ou seja, as raízes do conhecimento. Muitas vezes, mostro como foi a construção do saber em questão. Uma situação é no início do conteúdo de eletrostática que faço um relato desde a primeira concepção dos fenômenos elétricos (cargas elétricas), até a ideia de cargas elétricas positivas e negativas. Já trabalhei em turmas de $3^{\circ}$ ano a encenação de peça teatral sobre principais conteúdos da eletricidade e do magnetismo." (Professor de Física).

"História em quadrinhos; leitura de livro paradidático; debates." (Professor de Física).

"Aula expositiva introdutória de grade e debates com temas correlatos." (Professor de Biologia).

"Leitura de textos históricos; simulação de episódios; reprodução de experimentos clássicos; discussão de filmes e artigos científicos." (Professor de Física).

"Não trabalhei de forma completa apenas da forma de tópicos do ponto de vista histórico como a síntese da amônia." (Professor de Química).

"Sim. Tentei apresentar aos meus alunos o desenvolvimento de alguns conceitos a partir da evolução histórica de determinados aparatos/dispositivos. Na ocasião, utilizei um vídeo que trata da "Guerra das Correntes" discutindo inclusive filosoficamente o início, a ocorrência e o fim da tal guerra." (Professor de Física).

Do grupo investigado, apenas um professor respondeu que ainda não utilizou a HFC em sua prática docente. Isso mostra que a inserção da HFC no ensino de Ciências (Física, Química e Biologia) acontece de maneira heterogênea entre os profissionais analisados, no entanto, destaca-se que existe uma abordagem introdutória, ou em tópicos, na exposição de alguns conteúdos em sala de aula, principalmente entre os professores de Física.

\section{CONSIDERAÇÕES FINAIS}

Com base nos dados obtidos através da aplicação dos questionários com docentes das áreas de Ciências (Química, Física e Biologia) do IFRN - Campus 
Caicó, obteve-se resultados significativos quanto à investigação da inserção de tópicos da História e Filosofia da Ciência (HFC) nas aulas das referidas disciplinas no Ensino Médio Integrado ao Técnico, tendo em vista que a maior parte dos professores participantes da pesquisa tem utilizado em suas aulas a HFC e demonstrado interesse sobre a temática.

No entanto, o público pesquisado relatou que a principal dificuldade em inserir este conteúdo na sala de aula é a falta de um material didático adequado e de qualidade, abordando a HFC, uma vez que a formação docente pouco explora o tema e os livros didáticos do Ensino Médio não encaixam este conteúdo de forma satisfatória na inserção de tópicos sobre o tema na prática profissional de cada área.

Por fim, observou-se que as escolas, atualmente, no Brasil, preocupam-se mais com os exames de ingresso no Ensino Superior, como o Enem, tornando a carga horária dessas disciplinas pequena, fator que dificulta, de uma forma geral, a introdução da HFC nas aulas de Ciências. Assim, este Projeto de Pesquisa também faz parte de um uma proposta mais ampla por meio do GEPEF, no caso de intervenções pedagógicas que contemplem a inserção de tópicos da HFC nas salas de aula dos docentes de ciências no IFRN - Campus Caicó.

\section{REFERÊNCIAS}

BRASIL. Ministério da Educação. Secretaria da Educação Média e Tecnológica. Parâmetros Curriculares Nacionais $+(\mathrm{PCN}+)$ - Ciências da Natureza e suas Tecnologias. Brasília: MEC, 2002.

FELTRE, R.. Fundamentos de Química: vol. único. 4.ed. São Paulo: Moderna, 2005.

GIL-PÉREZ, D. Contribuición de la Historia y de la Filosofía de las Ciencias al desarrollo de un modelo de enseñanza/aprendizaje como investigación. Enseñanza de las Ciencias, v. 11, n. 2, p. 197-212, 1993.

LOPES, S.; ROSSO, S. BIO. São Paulo:Saraiva, 2016.

LONDERO, L. A história e filosofia da ciência na formação de professores de física: controvérsias curriculares. História da ciência e ensino: construindo interfaces. Volume 11, p. 18-32, 2015.

MARTINS, A. F. P. História e Filosofia da Ciência no ensino: há muitas pedras nesse caminho.... Cad. Bras. Ens. Fís., v. 24, n. 1: p. 112-131, 2007. 
MARTINS, R. de A. Introdução: a história das ciências e seus usos na educação. In: SILVA, C.C. (Org.) Estudos de história e filosofia das ciências: subsídios para aplicação no ensino. São Paulo: Editora Livraria da Física, 2006.

MATTHEWS, M. R. História, Filosofia e Ensino de Ciências: a tendência atual de reaproximação. Cad. Cat. Ens. Fís., v. 12, n. 3: p. 164-214, 1995.

MÁXIMO, A. R. L.; ALVARENGA, B. A.. In: Física - Coleção de olho no mundo do trabalho. A Física no campo da ciência. São Paulo: Scipione. 2003.

PEDUZZI, L. O. Q.; Martins, P. A. F.; Ferreira, J. M. H. Temas de História e Filosofia da Ciência no Ensino. Natal: EDUFRN, 2012.

PEDDUZZI, L. O. Q. Sobre a utilização didática da História da Ciência. In: PIETROCOLA, M. Ensino de Física: conteúdo, metodologia e epistemologia numa concepção integradora. Florianópolis: Editora da UFSC, 2001.

ROSA, C. A. P.. História da Ciência: da antiguidade ao renascimento científico. 2.ed. Brasília: FUNAG, 2012.

SILVA, Boniek Venceslau da Cruz. História e Filosofia da Ciência como subsídio para elaborar estratégias didáticas em sala de aula: um relato de experiência em sala de aula. Revista Ciências \& Ideias. Volume 3, n.2, p.1 - 14, 2011.

SILVA, Boniek Venceslau da Cruz. A História e Filosofia da Ciência na formação dos professores: um estudo no curso de física da UFPI. Revista Ciências \& Ideias, Vol. 5, n.1, p.39 - 50, 2014.

SILVA, Í. B.; TAVARES, O. A. O. Uma Pedagogia Multidisciplinar, Interdisciplinar ou Transdisciplinar para o Ensino/Aprendizagem da Física. Revista Holos - IFRN, Volume 21, p. 4-12, 2005.

VANNUCCHI, A. I. História e Filosofia da Ciência: da teoria para a sala de aula. 1996. 131f. Dissertação (Mestrado em Ensino de Ciências - modalidade Física) - Instituto de Física e Faculdade de Educação, Universidade de São Paulo, São Paulo. 


\section{MINISTÉRIO DA EDUCAÇÃO}

Instituto Federal de Educação, Ciência e Tecnologia do Rio Grande do Norte Campus Caicó

Grupo de Estudo e Pesquisa em Ensino de Física do IFRN - Campus Caicó

QUESTIONÁRIO ADAPTADO DE MARTINS (2006).

TEMA: História e Filosofia da Ciência no Ensino Médio

Identificacão do docente on estagiário:

Nome:

Formação: Idade:

Tempo de serviço:

1) Você tem interesse em estudar o tema História e Filosofia da Ciência?

$\sqcup \operatorname{Sim}$

$\sqcup$ Não

Em parte (explique)

2) Já cursou alguma disciplina (na UFRN, UERN ou no IFRN) ou fez algum outro curso que abordasse História e Filosofia da Ciência?

- $\operatorname{Sim}$

$\square$ Não

Qual(is)?

3) Você acha importante que tópicos da História e Filosofia da Ciência estejam presentes no livros didáticos e consequentemente nas aulas do ensino médio?

- $\operatorname{Sim}$

「 Não

Em parte Por quê? 
4) Na sua opinião, quais as principais dificuldades para se trabalhar com a História e Filosofia da Ciência no ensino médio?

5) Dos conteúdos curriculares da Física, da Química ou da Biologia no ensino médio, qual (ou quais) você considera mais dificil de ser trabalhado através da incorporação de tópicos da História e Filosofia da Ciência? E qual (ou quais) o mais fácil?

6) [Somente para quem faz estágio de regência ou é professor] Você, como professor, já tentou trabalhar tópicos de Histónia e Filosofia da Ciência na sua prática docente? Poderia relatar o que você fez de maneira mais específica (que tipo de atividade realizou)? 